\title{
What Matters Most? \\ Factors Influencing International Students' Satisfaction towards Cafeteria Foods
}

Doi:10.5901/mjss.2016.v7n4p

\author{
Noor Azimin Zainol \\ Janaga Seladorai
}

\begin{abstract}
Senior Lecturer, School of Tourism, Hospitality and Environmental Management
College of Law, Government and International Studies (COLGIS)

Universiti Utara Malaysia, Sintok Kedah 06000 Malaysia

Email: azimin@uum.edu.my
\end{abstract}

\begin{abstract}
The Malaysian government is focusing on developing education tourism to boost tourist arrivals. Apart from acquiring education, students' well-being in terms of food-consumption is a major fragment in a student's life. This paper puts emphasize on evaluating tourist resources as a component of tourism development through identification of international students' demands on food and how the foodservice suppliers should adjust to this. In particular, it will address international students' satisfaction towards cafeteria foods in university foodservice in Malaysia via extracting the salient factors that matters most in their evaluation of quality food and food price. Qualitative approach via open ended comment cards were distributed among 55 international students during April 2013 and content analysis was done on the feedbacks gathered. Based on the findings, majority of international students were dissatisfied with the taste, nutrition, hygiene, temperature, freshness and price of the food served by the cafeterias. This study will add to the under-researched area of foodservice sector academically and practically via identification of factors which international students' think are important as quality food with acceptable price towards their satisfaction in cafeteria dining. This will benefit the university foodservice operators in providing best practices as one of the tourism suppliers in enhancing tourism development.
\end{abstract}

Keywords: Food quality, food price, international student satisfaction, cafeteria food

\section{Background of Study}

Tourism is seen as a vehicle for a country's social and economic development based on the abundant advantages they may convey. Tourism industry is an important foreign exchange earner, contributing to economic growth, attracting investments, providing employment opportunities whilst also stimulating the redistribution of wealth. As a part of tourism development strategy, the Malaysian government is focusing on education tourism for getting more international students to study locally. Apart from acquiring education, students' well-being in terms of food-consumption is a major fragment in a students' life. Researches on university cafeterias are limited despite their major role in the university life among students. According to Andaleeb and Caskey (2007), university foodservice is one of the largest sectors of the foodservice industry. University cafeteria is a place where students spend approximately 5 hours a week (Kathryn, 2010). Amongst the main considerations of the on campus foodservice operators are how to maintain food quality and price to attract potential customers.

In the Malaysian context, the university food service management is facing crisis as students are dissatisfied with the food quality and price offered by the university food operators (Abdullah, Mansor, \& Naba, 2012). This is similar to a research conducted by Xi and Shuai (2009) which discovered that food quality, price and value are the main factors leading to students' dissatisfaction during patronizing the university cafeteria. In line with this, international students are dissatisfied with the existing cafeteria service provided by the food operators in UUM, based on researcher's observation, feedback from international students, and feedback from food operators. Therefore, this paper puts emphasize on evaluating tourist resources as a component of tourism development through identification of international students' demands on foods and how the foodservice suppliers should adjust to this. In particular, it will address international students' satisfaction towards cafeteria foods in university foodservice in Malaysia via extracting the salient factors that matters most in their evaluation of quality food and food price. It is important to analyze the impact of university's cafeteria services to ensure that UUM international students receive the greatest benefits from the cafeteria as part of their spending. 


\section{Literature Review}

Food is an important element which human beings and animals depend on for their physiological needs to survive. Food is a necessary nutrient for human body, thus failure to supply body with sufficient amount of food may result in diseases and death. University food service becomes one of the services that need to be considered in order to gratify students by providing food in universities. According to Ruetzler and Taylor (2011), a significant segment of university and college campus enrollments are international students. In Malaysia's effort to boost edu-tourism, Education Minister Tan Sri Muhyiddin Yassin announced that the Ministry of Higher Education (MOHE) aims to attract at least 200,000 international students to education institutions in Malaysia by 2020. This signifies the importance of enhancing tourist resources, including food suppliers to support the nation's integrated and cumulated development. To date there are a total of 2067 students (postgraduates and undergraduates) from 40 countries which are enrolled in University Utara Malaysia (UUM) to further their studies. Hence, maintaining food quality and food price in attracting international students are amongst the main consideration of the on campus food service operators.

Food quality is defined as a "combination of attributes or characteristic of a product that have significance in determining the degree of acceptability of the product to a user" (Ferree, 1973; Ploeger \& Angelika, 1996). In several empirical studies, food quality has emerged as the most essential key attribute of customer satisfaction (Clark \& Wood, 1998; Mattila, 2001; Namkung \& Jang, 2007; Peri, 2006; Sulek \& Hensley, 2004). There are various attributes of food quality which had been discussed in past researches. These includes taste, health options, freshness, presentation, quality of ingredients, safety, portion, halal, nutrition, menu variety, aroma, temperature, innovative menu items, hygiene, authentic food and texture.

On the other hand, food price is defined as the value that we get from an exchange, which can be in the form of tangible (product) or intangible (service) and price function is an indicator of quality (Levis \& Shoemaker, 1997). Price is the most important element in restaurant industry in determining customer satisfaction because customer estimate the value of the product or service obtained through price. Monroe (1989) depicts that the price of the items listed on the menu influence customer satisfaction. Moreover, price has been considered as an important element in explaining customer behaviors (Han \& Ryu, 2009).

Food quality and food price are seen as determinants of customer satisfaction while dining. Customer satisfaction is defined as customer's fulfillment response which customer judge on overall contentment level of utilization regarding to fulfillment provided from product or service (Oliver, 1997). Howard and Seth (1969) earlier contends that customer satisfaction is described as the appropriateness of the remuneration received in exchange for the service experienced. Based on this, customer satisfaction has become one of the most important marketing priorities generally assumed to be the most influential predictor of customer loyalty, of repeat sales and positive word of mouth (Han \& Ryu, 2009).

This study is a part of a bigger study done to explore salient factors which international students perceive as important in determining their satisfaction towards cafeteria foods as a part of tourism development resources. As there are limited studies done pertaining to this area, a preliminary study was deemed as feasible to be conducted.

\section{The Preliminary Study}

In order to explore the research problem at hand, a preliminary study was conducted to acquire some insights in the research idea. In particular, the purpose of the preliminary study was to attempt to surface some key issues surrounding the international students' satisfaction towards food quality and food price in university cafeterias. Due to the exploratory nature of the study, qualitative method was executed to achieve the results acquired. Patton and Cochran (2002) stated that qualitative research is depicted by its objectives, which is associated to understanding some aspect of social life and its methods which normally initiate words, rather than numbers, as data for analysis. According to Hancock, Ocklefod, and Windridge (2009) a qualitative approach aims to discover and explain the uniqueness of each particular situation by explaining and understanding the context specific phenomenon through naturalistic, qualitative inquiry.

The preliminary study involved interviews conducted on international students in UUM cafeterias. The interviews were conducted by asking the international students to answer a set of open ended questions (via comment cards) regarding their experience on food quality and food price during patronizing in UUM cafeterias. The interviews were essential in order to provide an overview of the evaluation process of the UUM cafeterias experience. In this instance, the interviews highlight which elements are important in judging the outcome of patronizing UUM cafeterias. During this phase, the respondents were asked to recall their experiences during patronizing in UUM cafeterias, so that the salient attributes that are related to the key constructs are established. By asking open ended questions and using appropriate probing, the respondents are not constrained to a fix set of answers. Hence, a large amount of more detailed and 
accurate data representing related to specific issues can be obtained (Marshall and Rossman, 1999).

\subsection{Research Instrument Design - Comment Card}

The aim of this qualitative method was to explore the international students' experiences of the UUM cafeterias in a way by which constructs are used to evaluate these experiences. Hence, an initial pre-data collection was conducted by distributing comment cards to the international students to gain their feedback regarding their satisfaction towards food quality and food price while patronizing in UUM cafeterias.

The comment card was designed in a simple format which consists of questions regarding experience in UUM cafeterias on food quality and price. The title 'Guest Comment Card UUM Cafeteria' was written on the top of the comment card. Space was given in the comment card to fill in their suggestions. The comment card framework was designed in a simple format so that the questions asked in the comment card is easy to understand and the researcher did not wish to take much time of UUM international students to fill up the comment card.

The purpose of having a planned and well-written comment card is to allow the international students to express their valuable opinion or feedback on food quality and food price provided in UUM cafeterias. The comment card system is a great way to collect testimonials regarding dissatisfaction or complains on foodservice in UUM from international students which are very useful to conduct this study at investigating the relationship of food quality and food price on international students' satisfaction in UUM cafeterias. An example of comment card distributed to international students is forwarded in Figure 1.1.

Figure 1.1: Guest Comment Card

\begin{tabular}{l}
\hline \multicolumn{1}{c|}{$\begin{array}{c}\text { Guest Comment Card } \\
\text { UUM Cafeteria }\end{array}$} \\
Your experience in UUM cafeterias: \\
Food Quality \\
\hline$\overline{\text { Price }}$ \\
\hline Suggestion \\
\hline
\end{tabular}

\subsection{Data Collection}

Respondents were selected based on judgemental sampling technique. This technique depends on the ability of the researcher to identify respondents who have the required information or experience with the research topic (Collis and Hussey, 2003). This technique is considered appropriate when insights into a subject matter are sought (Churchill, 1999). In this study, the researcher identified a number of international students who had been patronizing UUM cafeterias daily, particularly those who consume food in UUM cafeterias which are familiar with food quality and food price. In terms of language, the interviews was conducted in English as the respondents are from foreign countries.

Data was collected within three weeks period in April 2013. Comment cards were distributed to 61 respondents who dine in UUM cafeterias to answer a set of open ended questions regarding their experience on food quality and food price during patronizing in UUM cafeterias. Comment cards were distributed to seven cafeterias where most of the international students were found patronizing in the cafeterias. From the 61 comment cards selected, only 55 comment cards were applied in this study. 55 comment cards out of 61 were selected to use because the response to the remaining 6 comments cards were not clear and respondents did not answer appropriately.

\section{Data Analysis - Content Analysis}

As this phase is a qualitative phase via applying customer comment cards, content analysis was applied based on 
feedbacks given. Content analysis method is being extensively utilized in qualitative research technique for analyzing data and interpreting its meaning (Hsieh \& Shannon 2005; Schreier, 2012). As a research method, it signifies a systematic and objective mean of explaining and quantifying phenomena (Schreier, 2012). Qualitative content analysis is used to scrutinize text data. A requirement for successful content analysis is that data can be reduced to concepts that explain the research phenomenon by establishing categories, themes, concepts, a model, conceptual system or conceptual map (Weber, 1990; Hsieh \& Shannon, 2005).

Kondracki and Wellman (2002) contend that text data for qualitative content analysis are probably in verbal, print or electrical form, interviews, observation, focus group and might have been derived from narrative responses, open-ended survey questions or printed media such as magazines, books and articles. As it is associated to survey research, content analysis is a research method that is pertained to the verbatim responses or feedback provided to open-ended questions in order to code those answer into meaningful set of categories which will be used to further quantitative statistical analysis. Based on explanation given above, text data provided from open-ended comments from comment cards will be analyzed.

There are several steps involved in qualitative content analysis process which comprises three main phases: preparation, organization and reporting (Elo, Kaariainen, Kanste, Polkki, Utriainen \& Kyngas, 2014). The data analysis of this study begins with collecting and preparing, organizing or determining of data into categories or themes using data coding and lastly data is reported and presented in the form of discussion or tables (Creswell, 2007). The preparation phase starts in collecting appropriate data of content analysis, making sense of the data and selecting the unit of analysis (Elo, Kaariainen, Kanste, Polkki, Utriainen \& Kyngas, 2014). Determining on what to examine in detail and sampling considerations are imperative factors before choosing the unit of analysis.

The unit of analysis indicates the basic unit of text to be classified during content analysis. Messages or feedbacks have to be unitized before they can be coded. Unitizing entails by describing the units, separating them along their boundaries and classifying them for subsequent analysis (Krippendorff, 1980). Qualitative content analysis usually uses themes as the unit analysis. Based on this, thematic units are identified associating to a specific structural definition of content of comments or feedbacks, explanation or interpretation (Krippendorff, 1980).

Next phase is the organizing phase which involves generating categories or themes using data coding. Kreppendorff (2004) described coding as the "transcribing, recording, categorizing or interpreting of given units of analysis into terms of a data language so that they can be compared and analyzed" (p. 220). The coding process ascertains that the meanings of the resulting records are available to others, which provides for the interpretability of the research findings. During this phase, the respondents were asked to recall their experiences during patronizing in UUM cafeterias. This process has established a list of food quality attributes commented by the participants in the comment card. Under the first category, eight themes are analyzed which comprises of taste, nutrition, freshness, aroma, temperature, hygiene, portion and texture. The elements will be discussed further in the analysis section.

\subsection{Analysis - Demographic profile}

The total amount of respondents who participated in this qualitative stage was 61 UUM international students. Of these 61 surveys, 55 were completed while the other six incomplete comment cards were unusable, hence discarded from this study. These unusable comment cards were due to the forms were returned back as blank and the feedback in comment cards were not clearly stated. The information of the demographic profile of respondents is shown in Table 1.1. Of those responded, 35 respondents were male (63.6\%) and 20 respondents were female (36.4\%). 19 of the target respondents were less than 19 years old (3.6\%). 16 of them were between 20-29 years old (29.1\%). Most of the respondents were in the age range of 30-39 years old, which had 23 respondents (41.8\%). 11 respondents were between 40-49 years old (20\%) and the remaining three respondents were between 50-59 years old. In terms of religion of the respondents, 31 respondents were Muslims (56.4\%) whereas 24 respondents were Non-Muslim (43.6\%). With respect to the education background, 16 respondents are postgraduate students (29.1\%) while 39 respondents were undergraduate students (70.9\%).

As shown in Table 1.1, most of the respondents were from Nigeria, which had 12 respondents (21.8\%) followed by Yemen, 11 respondents (20\%). Indonesia with of nine respondents (16.4\%), seven respondents were from China $(12.75 \%)$ and Pakistan shows six respondents (10.9\%). Algeria and Jordan had four respondents each (7.3\%). Only one respondent originated from Philippines and Thailand. 
Table 1.1: The profile of respondents reported by gender, age, religion, education level and origin.

\begin{tabular}{|c|c|c|c|}
\hline & Variables & Frequency $(n=55)$ & Percentage (\%) \\
\hline Gender & $\begin{array}{l}\text { Male } \\
\text { Female }\end{array}$ & $\begin{array}{l}35 \\
20\end{array}$ & $\begin{array}{l}63.6 \\
36.4\end{array}$ \\
\hline Age & $\begin{array}{c}<19 \\
20-29 \\
30-39 \\
40-49 \\
50-59 \\
>60\end{array}$ & $\begin{array}{c}2 \\
16 \\
23 \\
11 \\
3\end{array}$ & $\begin{array}{c}3.6 \\
29.1 \\
41.8 \\
20 \\
5.5\end{array}$ \\
\hline Religion & $\begin{array}{c}\text { Muslim } \\
\text { Non- Muslim }\end{array}$ & $\begin{array}{l}31 \\
24\end{array}$ & $\begin{array}{l}56.4 \\
43.6\end{array}$ \\
\hline Education level & $\begin{array}{l}\text { Postgraduate } \\
\text { Undergraduate }\end{array}$ & $\begin{array}{l}16 \\
39 \\
\end{array}$ & $\begin{array}{l}29.1 \\
70.9 \\
\end{array}$ \\
\hline Origin & $\begin{array}{c}\text { Nigeria } \\
\text { Yemen } \\
\text { Indonesia } \\
\text { China } \\
\text { Pakistan } \\
\text { Algeria } \\
\text { Jordan } \\
\text { Philippines } \\
\text { Thailand }\end{array}$ & $\begin{array}{c}12 \\
11 \\
9 \\
7 \\
6 \\
4 \\
4 \\
1 \\
1\end{array}$ & \begin{tabular}{c|}
21.8 \\
20 \\
16.4 \\
12.7 \\
10.9 \\
7.3 \\
7.3 \\
1.8 \\
1.8 \\
\end{tabular} \\
\hline
\end{tabular}

\subsection{Analysis - Comment Card Findings}

Based on the content analysis process of the comment cards feedbac, some important themes which relate to food quality based on previous literature were revelaed. These themes include taste, nutrition, freshness, aroma, temperature, hygiene, portion and texture. Food price on the other hand, was identified as an independent construct in relating to students' satisfaction on cafeteria foods. These themes are discussed in turn below.

\subsubsection{Food quality}

\subsubsection{Taste}

Respondents were asked to state their experience while dining in UUM cafeterias. From the feedback, one of the most obvious negative experiences that influence international students' satisfaction at UUM cafeterias was taste. The feedback obtained from the comment cards indicate that most of the international students are not satisfied with the food taste provided by UUM food operators. Respondent complainted that the taste of food provided or cooked by UUM food operators do not meet their expectation which is not tasty. Terms such as "spicy", "sweet" and "salty" were associated with food taste by the respondents in the comment cards. For example, respondents claimed "most of the food dishes are sweet which are not liked by the international students" and "taste of the food spicy and salty not preferable". The term used in the comment card by most respondents relating food taste were "not liked", "food taste bad", "Not preferable" has lead to negative comments towards food taste. Most of the feedback obtained from the international students regarding food taste leads to dissatisfaction. Some examples of responses being given are as follows:

"Food taste bad".

"Taste of the food spicy and salty and lack of nutrition".

\subsubsection{Nutrition}

Nutrition refers to offering healthy options whilst also providing nutritious and healthy food. Nutrition plays a vital role to human being which provides energy and healthy body. Responses obtained from the comment cards regarding nutrition experience by the international students were quite disappointing. Many respondents experience the lack of nutrition in the food provided by the UUM cafeterias which were difficult for them to consume. The feedbacks from comment cards 
consist of food in cafeterias are not nutritious, too much oil, sugar and salt contents are high. International students experienced that food served in UUM cafeterias are lack of nutrition which they do not have the appetite. The example of word used to explain food nutrition in comment cards were "lack of nutrition", "nutrition not gain appetite" and "Nutrition not so satisfied" relates to negative view. These negative views showed international students encounter unpleasant experience while dining in UUM cafeterias. Some examples of responses concerning nutrition being given are as follows:

"There is no nutrition at all".

"Nutrition and freshness is not good the food looks like not hygiene anymore".

\subsubsection{Freshness}

Freshness has been acknowledged by the respondent during their experience while dining in UUM cafeterias. Comments on freshness contain several negative feedbacks from the international students. The feedback written by the international students on food freshness covered issues of vegetables, meat and shrimp cooked or served by food owners in cafeterias are not fresh. The phrase used to describe food nutrition in the comment card by most respondent were "freshness not so good", "not fresh" and "little no freshness" has lead to negative comments towards food nutrition. These negative feedbacks have indirectly leads to dissatisfaction of international students towards food quality while consuming food in cafeterias. Some examples on feedback about freshness are as follows:

"Freshness is not so good such for vegetables".

"Some ingredients is not fresh like shrimp"

\subsubsection{Aroma}

Aroma plays a significant role in the overall sensory perception of food product. The word "smell" and "stink" were used by respondents in the comment cards to explain their experience. Hence, the term "aroma" is forwarded as an important theme which relates to food quality. Aroma is a significant element of food quality that influences international students' satisfaction in UUM cafeterias. The feedback gained from the comment cards specify international students are not satisfied with food aroma served by UUM food owners. Respondents point out that the food aroma in UUM cafeterias are not appealing and do not suit them. Respondent encounter that the food served in cafeterias having an unpleasant smell which the food seem to smell spoilt or expired which then leads to unfavourable smell. "Aroma not good" and "Smell like spoilt" were highlighted by respondents in comment cards in describing food aroma. From these findings, researcher can see that international students encounter negative experience while dining in UUM cafeterias. Some examples of responses being given are as follows:

"Smell of food very bad, aroma of food likes expired date and sometimes after you eat it, you become vomit".

"Aroma not good (vegetable stink: smell spoilt)".

\subsubsection{Temperature}

International students' comments indicate some concern on food temperature experienced during patronizing in UUM cafeterias. Temperature is one of the vital attributes in food quality which customers consider during purchasing or consuming food in cafeterias. The terms such as "warm" and "cold" were related with food temperature by the respondents in the comment cards. The feedback from the comment cards revealed negative experience faced by the international students in UUM. They complaint that food temperature displayed on the table, or served in UUM cafeterias are not consistent and not in a good condition. They even complaint that the food provided by UUM food owners are very bad and cold which the international do not have the appetite to consume. Food temperature in UUM cafeterias need to be taken into consideration by the food owners so that the international students would not face difficulty while consuming food in cafeterias. Some examples on feedback about temperature are as follows:

"Temperature not consistent, most of the time cold-very bad.

"Food temperature in cold condition not appetite to eat". 


\subsubsection{Hygiene}

In the comment card findings, words such as "cleanliness" and "uncovered" were being emphasized on food quality. Based on this, an important theme in food quality which is food hygiene is established. A number of international students reported that they encounter problem in food hygiene in UUM cafeterias. Comments on food hygiene contain several negative feedbacks from the international students. The feedback written by the international students on food hygiene entails food displayed on the table are not covered with cover lid where flies tend to perch on the food. Besides that, the food owners should follow the food safety rules in preparing the food, for instance cleanliness should be highlighted during making or preparing the food by using glove. The example of phrase used to explain food hygiene in comment cards were "hygiene is not so good" and "food is always uncovered" relates to negative view. These feedbacks have leads to international students' dissatisfaction towards food quality. Some examples of responses being given are as follows:

"The food is always uncovered.

"The problem is the cleanliness of the foods, in some cafeterias there are so many flies on the food and sometimes there are cockroaches near the cafeterias".

\subsubsection{Portion}

Evidence regarding dissatisfaction of international students towards food portion provided by the UUM food owners was also obtained from their feedback. Customer comment cards findings revealed respondent experience dissatisfaction on food portion served in UUM cafeterias were not worth for money. The feedbacks obtained from the international students indicated that UUM food owners provide food in small portion while being charged overly and also food is being served in different amount in different days. Some examples on feedback about food portion are as follows:

"Food portion not same provided in different days".

"Food provided very little but charge the food charge over".

\subsubsection{Texture}

Texture is an important element of food quality that influences customer satisfaction in UUM cafeterias. Texture has been acknowledged by the respondent during their experience while consuming food in UUM cafeterias. The responses imply that international students had negative experience which they had point out several negative feedbacks. The feedbacks obtained from the respondent indicate that texture of food is very bad which is not in a good taste. Respondent mention that they do not prefer or like the food texture in UUM cafeterias. Some examples of responses being given are as follows:

"Texture of the food very bad need to improve".

"Texture very bad- roti canai (toasted bread) is very hard and not nice to eat".

\subsubsection{Price}

Price is the second main category which needs to be analyzed in this study base on comment cards. Herein, the respondent encounter unpleasant experience while purchasing food in UUM cafeterias. The comments expressed by the respondent regarding food price in UUM have created dissatisfaction among the international students. According to the comment cards findings, majority of the international students state that the prices offered by the UUM food owners are too expensive which they could not afford. Apart from that, they also indicate that the food is overcharged or sometimes the food owners tend to charge different price on different days for the same amount of food. Comment cards findings revealed that food price charged in UUM cafeterias are not worth for the food portion served. It means that, food owners tend to charge high for the small amount of food which the international students feel not worth. Some examples of responses on price being given are as follows:

"The price should be reduced to more considerate and due the issues is that at times food is been over charged".

"The price is too high. Demanding too much for a student like me. Price is unreasonable. How could afford this?' 


\section{Discussion and Conclusion}

The qualitative approach via content analysis is useful for exploring and understanding an under-researched social phenomenon such as international students' satisfaction towards food quality and food price in educational institution's foodservice cafeterias. Its holistic nature allows the study to construct reality based on interpretations of the context while its flexible nature permits the study to design qualitative investigation methods deemed most suitable.

In summary, the findings revealed that the majority of international students were dissatisfied with the taste, nutrition, hygiene, temperature, freshness and price of the food served by the cafeterias. They complaint that the food displayed on the table are not covered where flies tend to perch on the food. They also stated that the food served are too sweet and lack in nutrition which is difficult for them to consume. There were also complaints regarding food temperature during consumption. Apart from that, they also state that the food is overcharged. This study will add to the under-researched area of foodservice sector academically and practically via identifiying factors which international students' think as important in terms of quality food and acceptable price as a means for university's management in providing excellent foodservice for international students. The findings will be useful for university foodservice operators to know what their customers' satisfaction level ought to be and how to retain their patronage.

Thus, this study is hoped to contribute to the lack of academic studies done on university foodservice sector whilst also benefiting the university foodservice operators in providing best practices as one of the tourism suppliers in enhancing tourism development. All the food quality attributes mentioned by the participants via the qualitative effort will be tested on international students during a quantitative survey as the main instrument of the data collection so as to ensure the reliability of gathered data to complete the bigger part of the project.

\section{References}

Berelson, B. (1952) Content Analysis in Communication Research. New York: The Free Press.

Collis, J. \& Hussey, R. (2003) Business Research: A practical Guide for Undergraduate and Postgraduate Students. (2 nd ed). Basingstoke: Palgrave Macmillan.

Creswell, J. W. (2007) Qualitative Inquiry and Research Design: Choosing Among Five Approaches (2nd ed.). Thousand Oaks, CA: Sage.

Elo, S., Kaarianen, M., Kanste, O., Polkki. T., Utriainen, K., \& Kyngas, H. (2014). Qualitative content analysis: A focus on trustworthiness. Retrieved from sgo.sagepub.com/content/4/1/2158244014522633-pdf

Hancock, B., Ockleford, E., \& Windridge, K. (2009) "An introduction to qualitative research", The NIHR Research Design Service for Yorkshire \& the Humber.

Hsieh, H. F., \& Shannon, S. E. (2005) 'Three approaches to qualitative content analysis'. Qualitative Health Research 9(15): 1277-1288.

Kondracki, N. L., \& Wellman, N. S. (2002) 'Content analysis: Review of methods and their applications in nutrition education'. Journal of Nutrition Education and Behavior, 34(1): 224-230.

Krippendorff, K. (2004) Content Analysis: An Introduction to Its Methodology (2nd ed.). Thousand Oaks, CA: Sage

Krippendorff K. (1980) Content Analysis: An Introduction to Its Methodology. Beverly Hills, CA: Sage

Marshall, C., \& Rossman, G. (1999) Designing qualitative research (3rd ed.). Thousand Oaks,CA: Sage.

Mayring, P. (2000) Qualitative content analysis. Forum: Qualitative Social Research, 1(2). Retrieved from http://217.160.35.246/fqstexte/2-00/2-00mayring-e.pdf, page consulted July 28, 2008

McTavish, D.G., \& Pirro, E.B. (1990) 'Contextual content analysis'. Quality and Quantity, 24(1): 245-265.

Patton, M. Q., \& Cochran, M. (2002). A guide to using qualitative research methodology, Medecines Sans Frontières.

Schreier, M. (2012) Qualitative Content Analysis in Practice. Thousand Oaks, CA: Sage.

Tesch, R. (1990) Qualitative Research: Analysis Types and Software Tools. Bristol, PA: Falmer.

Weber R.P. (1990) Content Analysis. Basic Content Analysis (2nd ed.). Thousand Oaks, CA: Sage. 